\title{
DSM’ler Boyunca Travma Kavramının Seyri
}

\author{
Burçin Çolak ${ }^{*}$, Ahmet Kokurcan", Hüseyin Hamdi Özsan ${ }^{* *}$
}

\section{ÖZET}

Literatürde 'A ölçütü sorunu' olarak geçen Travma Sonrası Stres Bozukluğu'nun (TSSB) 'travma'yı tanımlayan ilk ölçütünün içeriği Ruhsal Bozuklukların Tanısal ve Sayımsal El Kitabının (DSM) üçüncü baskısında bu yana tartışılmakta ve her yeni DSM sürümüyle de değişikliğe uğramaktadır. DSM'nin üçüncü baskısından önce de travma ile ilişkili bozukluklardan bahsedilmiş olmakla beraber hem travmanın hem travma ile ilgili bozuklukların doğrudan tanımı yapılmamıştır. TSSB tanısında travma tartışmalı tek yönlü bir nedenselliğe işaret etse de merkezi önemini korumaya devam etmektedir. $\mathrm{Bu}$ makalede travmanın DSM sürecinde geçirdiği değişim incelenmiştir.

Anahtar kelimeler: Post travmatik stres bozukluğu, Psikolojik Travma, Stresli Yaşam Olayları

The Course of The Trauma Concept Throughout the DSMs

\section{ABSTRACT}

The 'Criterion A problem' has been a topic of debate since the introduction of PTSD in

*Araş. Görevlisi, Ankara Üniversitesi Tıp Fakültesi Psikiyatri Anabilim Dalı, Ankara

**Prof Dr. Ankara Üniversitesi Tıp Fakültesi Psikiyatri

Anabilim Dalı, Ankara
DSM-III and the definition of trauma has changed in every new DSM edition. Many psychiatric disorders were already accepted to be related to traumatic life events, thus the authors of DSM-I and II did not specifically identify a distinct category of traumatic disorders. The controversery also stems from etiological causality: wordings such as 'trauma related' or 'traumatic' generally refer to a definite causality in general medicine as well as psychiatry. In this article we will focus on the change of the concept of trauma in DSM process from first edition to last edition planned for publication in 2013.

Keywords: Post Traumatic Stress Disorder; Psychological Trauma; Stressful Life Events

\section{GiRiş}

19. yy ve 20. yy ilk yarısında "travma" kavramının fiziksel travma haricinde kullanımı kısıtlı olmuştur (Jones 2007). Günümüzde de tıp sözlüklerinde travma kelimesinin karşılığı "bedene dış bir etmen tarafından bir zarar gelmesi" olarak tanımlanır (Kocatürk 2005).Dışsal bir etken olan travmaya uğrayan sağlıklı bireyden beklenen bu sorunu halletmesiydi. Bu açıdan eğer bir kişi travma 
sonrası psikolojik sorun yaşıyor ise bu muhtemelen kişide zaten mental bir hastalık ya da yatkınlık olduğunu gösteriyordu. Kişinin ya ego gücü düşüktü ya da şizofreni benzeri biyolojik temelli olduğu düşünülen bir rahatsızlığı vardı; yani hastalığın 'asıl' nedeni bireyin ta kendisiydi (Jones\&Wessley 2005). $\mathrm{Bu}$ açıdan travmatik olayların psikolojik etkileri fazla önemsenmemiştir. Travmatik olayların fiziksel zarar dışında da sorunlara yol açabileceği fikri 1870 yılındaki Fransa ve Prusya savaşı sonrasında oluşmaya başladı. $\mathrm{Bu}$ hastalardaki bozukluklara ilk olarak "travmatik nevroz" tanısı önerilmiştir (Kardiner 1959). Birinci Dünya Savaşı'nda bomba şoku (shell shock) gibi terminolojiler travmanın kişiler üzerine ruhsal etkileri olduğunu ima etse de travma yaratan yaşam olayları üzerine dikkat çekilmemiş ve travma bozuklukları tetikleyen bir etmen olmaktan öte görülmemiştir. Aynı düşüncenin İkinci Dünya Savaşı öncesinde de devam ettiği görülmektedir (Jones 2007). Bu açıdan travma kavramının psikiyatri literatürüne girişi ve gelişimi klinisyenler için her zaman için önemli bir konu olmuştur (Yehuda\& McFarlane 1995). Yine travmanın tanımı da tartışmalara konu olmuş ve süreç içinde değişime uğramıştır. Bu değişimi yayınlanmış DSM'lerde izlemek mümkündür (Wilson 1994). Örneğin zorlu yaşam olaylarına "travma" denilmesi ilk defa DSM-III ile olmuştur ( APA 1980). Bu makalede biz "travma" kavramının DSM'nin ilk yayınlandığı tarih olan 1952 yılından telif açısından yayınlanması planlanan DSM-5'te de devam eden değişim seyrini gözden geçireceğiz.

\section{DSM-I}

DSM-I Amerika Birleşik Devletlerinde 2. Dünya Savaşı sonrası dönemin sosyo-politik ikliminde filizlenmiş bir dökümandır. İlk olarak Amerikan ordusunda bülten-203 olarak yayımlanan bir bildirinin Amerikan Psikiyatri Birliği tarafından sivil toplumda uygulanabilecek bir versiyonu aslında üzerinde pek de değişiklik yapılmadan yayımlanmıştır. $\mathrm{Bu}$ nedenle içeriğinin dönemin askeri görüşünden etkilenmesi kaçınılmazdır. DSM- 1'de 'Büyük Stres Reaksyonu' (Gross Stress Reaction) isimli bir tanıya yer verilmiştir. Buna göre öncelikli olarak travmatik olayın savaş sırasında meydana gelen bir olay olup olmadığı (askeri mercileri ilgilendirip ilgilendirmediği) kaydedilmeliydi. Dahası, bu olay savaş esnasında meydana gelmiş olsa bile patlama/felaket gibi çok büyük bir olay olmuş olmalıydı. Böylesine bir olaydan etkilenen kişi tamamen normal birisi olamazdı; olsa olsa 'hemen hemen normal' (more or less normal) bir kişi olabilirdi. Öte yandan bu tanı sınıfı psikojenik orijinli / organik sebebi götserilemeyen hastalıkların alt grubu olarak duruma bağlı ve 'geçici' olan bir 'kişilik bozukluğu' olarak değerlendirilmişti(APA 1952).

DSM-l'de bu başlık altında tanımlanmış olarak olay kavramı;

- Kişinin aşağıdaki özellikleri olan bir olaya maruz kalmış olması gerekir; Kişi ciddi bir fiziksel eksikliğe veya çok yüksek emosyonel strese sebep olan bir olaya maruz kalmalıdır (örneğin yangın, deprem, patlama vs).

- Stres yaratan olay savaş veya sivil bir felaket özel olarak belirtilmelidir.

DSM-I'in bu tanımı DSM-IV' ün travma tanımına benzemektedir. Ama özellikle olayın etkisinin geçici olduğunu, ortaya çıkan belirtilerin psikozdan nevroza değişkenlik gösterse de bir süre sonra belirtilerin ortadan kalkması gerektiğini metinde vurgulamıştır. Eğer geçmez ise bu tanının geçici bir tanı olduğundan hareketle başka bir tanı ile değiştirilmesi gerektiğini belirtmiştir. DSMl'deki olay tanımının yüzeysel olduğu ve özellikle savaş ve sivil felaketin belirtilmesi sadece büyük ölçekli olayları travma olarak kabul etmekte ve kişiler arası şiddet ve cinsel saldırı gibi olaylardan bahsetmemektedir(APA 1952). Bu durum savaş sonrası dönemin düşünsel atmosferini yansıtıyor olabilir.

\section{DSM-II}

1966 yılında DSM-II yayınlandığında İkinci Dünya Savaşının üzerinden uzun süre geçmiş olsa da bu süre Vietnam savaşının (1961- 
1975) kişiler üzerindeki sonuçlarını görecek kadar uzun değildi. Bu süreçte flashback gibi TSSD belirtileri daha iyi tanımlanmakla beraber DSM-II bu konuda hiçbir gelişme göstermemiş ve travmatik olay ve travmaya bağlı bozukluk düşüncesi DSM-l' den de geriye düşmüştür (Wilson 1994). İkinci Dünya Savaşı bitmiş ve toplumsal boyutta bir olay da kalmamıştır. Bu sebeple de dönemin yeni DSM'sinde böyle bir tanı kategorisine intiyaç kalmamıştır-(Jones 2007). Bu sebeple DSM-II psikolojik travma noktasında yeni bir şey söylememiş ve travma geçici uyum bozukluklarına sebep olan bir durum olarak değerden düşmüştür. Yine dikkati çeken bir başka nokta olayların büyük ölçekli, toplumsal olaylarla sınırlanmasıdır ve bireye özgü travma diye bir kavrama yer verilmemiştir( APA 1966).

DSM-II'nin travma ile ilişkili hastalık (travma kavramı kullanılmadan) tanımı şöyledir; altta yatan herhangi bir psikiyatrik hastalığı olmayan kişilerde çok yoğun ve baskılı bir çevresel olaya (overwhelming environmental stress) maruziyetten sonra çıkan belirtilerdir. Bu belirtiler stresli olay ortadan kalktıktan sonra yok olur eğer stres ortadan kalktıktan sonra devam ederse tanı değiştirilmelidir. Travmatik olay tanımı ayrı bir travma tanı kategorisi olmadığı için özellik göstermemektedir. DSM-II'nin bu açıdan travma tanımı oldukça muğlâk kalmıştır hatta travma ile ortaya çıkan tabloyu da uyum bozukluğu olarak sınırlamıştır. Örnek olarak verdiği olaylar arasında savaş istenmeyen gebelik gibi olaylar bulunur. Ganser sendromu gibi klinik tabloların bozukluğun tezahürü olabileceği vurgulanır. DSM-II'de ek bölüm 6'da ICD-8'de geçen majör hastalıklar bölümü eklenmiş ve birçok uyum bozukluğu yaratacak durumları sıralamıştır. Fakat bu olaylar ile uyum bozukluğu arasındaki ilişkiye işaret etmemiştir (APA 1966).

\section{DSM-III}

DSM-IIl de ilk defa TSSB ve buna bağlı olarak "travma" kavramı tanımlanmıştır (APA 1980). TSSB tanısı aslında nedensellik açıklamakta iddiası olmayan ve teoriye dayanmayan DSM-III için farklılık arz etmektedir. 1970 öncesi dönemde travmatik olaydan sonra oluşan psikiyatrik tablolar kişinin psikolojik ve biyolojik yapısı ile ilgiliydi ve travmatik olay sadece tetikleyiciydi. TSSB tanı kategorisinin tanımlanması ile birincil etyolojik sebep kişi merkezli olmaktan çıktı ve olay (travma) merkezli hale geldi (Turnbull 1998). TSSB'nin psikiyatrik bir tanı olarak DSM-IIl'e girmesinin yayımlandığı dönemin siyasi, entelektüel ve kültürel atmosferinden etkilendiği öne sürülür (Jones 2007). Bu dönemde Batı toplumunda psikiyatri için zorluk teşkil eden özgür irade ve bireysel sorumluluk gibi kavramlar sorgulanır hale gelmiştir. Dolayısıyla psikiyatrik belirtiler pekâlâ dış olaylara bağlanabilmeye başlanmıştır. Artık sıradan (normal, sağlıklı) birey olaylar karşısında güçlü durmak zorunda değildir. Normal birey anormal olaya anormal tepki verebilir. Böylece örneğin savaşlardan sonra psikiyatrik rahatsızlık yaşayan birçok kişi dış bir neden ile hasta 'olabildiler'. Buna karşın bu paradigma değişimi ile ikincil kazanç problemi ve tazminat davaları da gündeme geldi (Maier 2005). Bu sebeple travma-(örnek savaş sırasında yaşanan bir olayın) hemen hemen herkeste belirgin düzeyde sıkıntı yaratacak 'bariz' bir olay olarak tanımlandı. DSM-III TSSB'yi anksiyete bozuklukları ana kategorisi altında tanımlamıştır ve travma kriteri aşağıdaki gibi yapılmıştır(APA 1980);

Kriter A: Hemen herkeste belirgin düzeyde belirgin sıkıntı yaratacak bariz bir olayın varlığı olmalıdır.

"Hemen herkeste belirgin düzeyde sıkıntı yaratan olay" tarifi ile bozukluk önceki DSM'lerden farklı olarak anormal bir yaşam olayına verilen meşru bir tepkiye dönüşmüş oldu. Fakat kriterin ayrıntılı belirtilmemesi objektiflik tartışmasını gündeme getirdi(Maier 2006). "Hemen herkeste belirgin düzeyde sıkıntı yaratan olay " tanımı ve olayı travmatik yapan eşik halen belirsizdi. Bu sebeple DSMIII-R'de kavram örneklerle revize edilmiştir(APA 1987). 


\section{DSM-III-R}

Kriter A: Normal insan deneyiminin ötesinde, herkes için sıkıntı yaratan bir olay. Örnek olarak kişinin hayatına veya fiziksel bütünlüğüne tehdit, kişinin çocuğuna, eşine yakın akrabasına veya arkadaşlarına yönelik tehdit veya zarar verme, kişinin evine veya yaşadığı ortama zarar verme veya başka kişilerin kazara veya fiziksel şiddet sonucu yaralandığına veya öldürüldüğüne şahit olma verilebilir.

DSM-III-R metin bölümünde travmayı şöyle ayrıntılandırır; Bu durumlara sebep olan tablolar arasında işkence, tecavüz, savaş, deprem gibi doğal felaketler, fiziksel bütünlüğe tehdit oluşturan her türlü kaza, bombalama gibi olaylar sayılabilir. Yine de bazı olaylar sıklıkla TSSB yaparken (işkence) bazıları (trafik kazası) bazen TSSB ye sebep olur( APA 1987). DSM-III-R'deki revizyon ile amaçlanan travmatik olayın ciddiyeti ve hayatı tehdit eden yönünü vurgulamak ve stres yaratan olayın ciddiyeti ile ilgili soru işaretlerini azaltmak olmuştur. Normal insan deneyiminin ötesinde (gündelik yaşamda karşılaşılmayan) tanımının eklenmesi bu çabaya işaret etmektedir (Turnbull 1998) Yine de kavram bu düzeltmelere rağmen DSM-IV'te de revizyona gitmiştir(APA 1980).

\section{DSM-IV ve DSM-IV-R}

DSM-III-R ile travmanın tanımı ve hangi olayların travma olarak nitelenebileceği belirtilmiş olmakla beraber travma tanımında eksiklik olduğu düşünülmüş ve DSM-III ve DSM-III-R'de tek kriter olan travma tanımı DSM-IV'te iki kriterli hale gelmiştir. (APA 19942000).

DSM -IV'te travma kriteri;

Kriter A: Aşağıdakilerden her ikisinin de bulunduğu bir biçimde kişi travmatik bir olayla karşılaşmıştır.

1. Kişi, gerçek bir ölüm ya da ölüm tehdidi, ağır bir yaralanma ya da kendisinin ya da başkalarının fizik bütünlüğüne bir tehdit olayını yaşamış, böyle bir olaya tanık olmuş ya da böyle bir olayla karşı karşıya gelmiştir.

2. Kişinin tepkileri arasında aşırı korku, çaresizlik ya da dehşete düşme vardır. Not: Çocuklar bunların yerine dezorganize ya da ajite davranışla tepkilerini dışa vurabilirler.

Dikkat edilirse DSM-IV'te travma tanımı olayları daha özelleştirerek DSM-IIl'te olan tanımsal kavramları dışlamıştır (-DSM-III' teki "normal insanların deneyimlediği sıradan olayların dışında" ve "herkes için sıkıntı yaratan bir olay" kavramları çıkarılmıştır). Yani bir olayın travmatik olması için "normal insanların deneyimlediği sıradan olayların dışında" ve "herkes için sıkıntı yaratan bir olay" olmak zorunluluğu kalkmıştır. Onun yerine travmayı gerçek bir ölüm ya da ölüm tehdidi, ağır bir yaralanma ya da kendisinin ya da başkalarının fizik bütünlüğüne bir tehdit olayı olarak belirlemiş ayrıca yanına bireyin olaya vereceği öznel yanıtları da bir kriter olarak şart koşmuştur. Bu açıdan olaylara A1 tanımı ile objektivite kazandııılmaya çalışımaktadır. A2 kriteri ile de travmatik olaylara verilen cevaplarda öznelliğin reddedilemeyeceği vurgulanmıştır. Bu açıdan DSM-IV'te hem kavrama objektiflik kazandırmak hem de olayın yaşantılanmasında öznelliğin önemini vurgulamak adına yapılmaya çalışılan denge kurma çabası dikkat çekmektedir (APA1994Wilson 1994).

DSM-IV' ün farklarından biri de sekonder travmatizasyonu kabul ettiğidir. DSM-IIl'te örneklendirilse de tanı kriteri olarak ikincil travmatizasyonun varlığı DSM-IV ile meşru hale gelmiştir. Artık bir olayı öğrenmiş olmak, haberini almak, görmek gibi dolaylı yollarla da kişi travmaya uğramış kabul edilebilmektedir. Tabi bu durumda travmatik olay olarak nitelendirilecek olay tipleri çoğalmıştır (örnek; kişinin telefondan aldığı bir haber veya televizyondan izlediği bir görüntü dahi travmatik olay sayılmıştır). Yine A2 kriteri sayesinde travmatik olay tanımı öznelleşmiş bu da olay çeşitliğini arttırmıştır (örn; basit tıbbi müdahale ile giderilecek fiziksel darp DSM-III tanımı için travmatik olarak değerlen- 
dirilmeyebilecekken

DSM-IV

değerlendirilebilir hale gelmiştir). Böylece travmanın büyük ölçekli olaylardan bireysel olaylara kaydığı görülmektedir (APA 1994). Bu durumu insan haklarının yükselişinin DSM IIl'deki büyük yansımasının devamı olarak değerlendirmek mümkündür (Maier 2005). Tabi bu durum gündelik yaşamdaki zorlamaları travma olarak değerlendirmeyi kolaylaştırmıştır (Avina ve O'Donohue 2002, Ollf ve ark 2005).Yine öznel tepkilerin A2 kriterinde belirtilenlerle sınırlı olmaması da tanıyı karşılamakta zorluk yaratmaktadır. Bu gibi nedenlerden ötürü DSM-V'te travma tanımının tekrar değiştirilmesi planlanmaktadır.

\section{DSM-V}

2013 yılında yayınlanması planlanan DSM-V' te ise travma ile ilgili bozuklukların travma ve stresör ile ilgili bozuklar kategorisi altında tanımlanması önerilmektedir (APA 2010). Travma ile ilgili bozukluklar kategorisi DSM-l'de tanımlanan büyük stres reaksiyonu grubunun genişletilmiş haline benzemektedir. DSM-III ve sonrasında birbirinden ayrı olarak ele alınan travma ile ilgili klinik bozukluklarınTSSD anksiyete bozukluklarının altında, uyum bozuklukları kategorisi vs. tekrar bir grup altında birleştirilmesi planlanmaktadır. Yine bu kategoride tepkisel bağlanma bozukluğu gibi bozuklukların bulunması travma ve stres yaratan yaşantıları ve buna bağlı bozuklukları yeniden tanımlamakta ve DSM-l' deki gruplamaya geri dönüşe işaret etmektedir (APA 1952). Ayrıca önerilen sınıflama ile bu tanı grubu ICD sisteminde tanımlanan ağır stres reaksiyon ve uyum bozuklukları grubuna yakınlaşacaktır (WHO 2010).

DSM-5 taslağında kişinin öznel tepkisi dikkate alınmamış (DSM-IV'te bulunan A2 kriteri çıkarılmış), onun yerine, travmatik olay tanımını netleştirmek amacı ile olaylar ile karşılaşmanın yolları sıralanmıştır. DSM-5 taslağına göre kişinin kendisi olayı yaşamış, tanık olmuş olabilir. Yine olay başkasından duyulmuş olarak yakın bir arkadaş veya yakın bir akrabanın başına gelmiş olabilir. Bu takdirde ölüm olasılığı, şiddet veya kaza niteliğinin bulunması şartı olmalıdır. Yine olaylara elektronik medya, televizyon, film gibi görsel medya üzerinden maruziyet dışlanması önerilmektedir (APA 2010) Bu dışlamanın önerilmesi 11 Eylül sonrası olay maruziyetinin görsel medya aracılığı ile olması dolayısı ile genişleyen maruziyet yollarını sınırlamak için olabilir. Yine DSM-IV'te olmayan "doğrudan(directly)" teriminin eklenmesi ile olaya maruziyet çeşitliliği daraltılmıştır. Taslakta travmatik olay ile travmatik olmayan olay ayrımını objektif olarak yapma çabası dikkat çekmektedir. Önceki DSM'lerde olan "kendinin ve başkalarının fiziksel bütünlüğü" ifadesi kaldırımış ve ilk defa "cinsel şiddet" ifadesine yer verilmiştir. Kullanılan somut kavramlar (fiziksel bütünlüğe tehdit yerine cinsel travma gibi) ve A2 kriterinin dışlanması ile tanım netleştirilmeye çalışılmıştır. Böylece örneğin A2 kriterini karşılamayan ama travmaya uğramış kişiler de-anhedonik veya dissosiyatif belirtili TSSB için eski A2 kriteri problem teşkil etmekteydi- TSSB tanısını karşılayabileceklerdir.

\section{Sonuç}

DSM-l'den DSM-5'e giden süreçte travma ile ilgili bozuklar önce bir arada ele alınmış DSM-Il'de ise ayrıntılı biçimde tanımlanmamıştır. Dönemin siyasal iklimine uygun olarak başlangıçta sadece büyük ölçekli felaketler travma olarak tanımlanırken DSM-III ile beraber travmanın öznel deneyimi vurgulanmış ve travma ile ilişkili bozukluk kavramı netleşmiştir (Tablo1). Öte yandan bu netleşmenin davranış bilimlerindeki suni çevresel/biyolojik dikotominin etkisiyle fazla ayrışmış bir klinik tablo tanımlanmasına neden olduğu da öne sürülebilir. Gelecek DSM-5 sayesinde travma ile ilgili bozuklukların tek bir grupta toplanmasını bu suni ayrışmanın düzeltilmesi girişimi olarak ele alabiliriz. Hem bu toplanma hem de travma tanımındaki değişiklikler ile gen çevre etkileşim modelinin DSM-5 tarafından daha fazla ve daha doğru olarak dikkate alındığı söylenebilir. DSM5yayınlandıktan sonra travma kavramının seyri üzerine daha fazla şey söylemek mümkün olacaktır. 
Tablo 1: Travma Tanımındaki Değişimler ve Yorumu

\begin{tabular}{|c|c|c|}
\hline & Travma tanımı & Yorum \\
\hline DSM-I & $\begin{array}{l}\text { "Ciddi bir fiziksel eksikliğe veya çok } \\
\text { yüksek emosyonel strese sebep olan bir } \\
\text { olay" }\end{array}$ & $\begin{array}{ll}- & \text { Olay tanımı net değil } \\
\text { - } & \text { Bireysel travma kavramı müphem } \\
\text { - } & \text { Büyük bir olaya(savaş, deprem) maruziyet vurgusu }\end{array}$ \\
\hline DSM-II & "Ezici/kahredici çevresel bir olay" & $\begin{array}{ll}- & \text { Olay tanımı DSM-I den daha müphem } \\
\text { - } & \text { Olay ile ortaya çıkan klinik uyum bozukluğu ile } \\
\text { sinırlı } & \end{array}$ \\
\hline DSM-III & $\begin{array}{l}\text { "Hemen herkeste belirgin düzeyde } \\
\text { belirgin sikintı yaratacak bariz bir olay" }\end{array}$ & Genel geçer bir tanım çabası dikkat çekmekte \\
\hline DSM-III-R & $\begin{array}{l}\text { "Normal insan deneyiminin ötesinde, } \\
\text { herkes için sıkıntı yaratan bir olay" }\end{array}$ & $\begin{array}{l}\text { - Tanımı netleştirmek adına olaya maruziyet şekilleri } \\
\text { belirtilmiş } \\
\text { • Gündelik yaşamda karşılaşılmayan olay tanımı ile } \\
\text { olayı sınırlama çabası var }\end{array}$ \\
\hline $\begin{array}{l}\text { DSM-IV } \\
\& \\
\text { DSM-IV-R }\end{array}$ & $\begin{array}{l}\text { "Bir ölüm ya da ölüm tehdidi, ağır bir } \\
\text { yaralanma ya da kendisinin ya da } \\
\text { başkalarının fizik bütünlüğ̈ün bir tehdit } \\
\text { olayı" }\end{array}$ & $\begin{array}{l}\text { Kişinin verdiği öznel tepkiyi belirterek travmada } \\
\text { öznel tepkilerin önemini vurgulamak } \\
\text { - } \\
\text { Dolaylı travmatizasyonun kabulü }\end{array}$ \\
\hline $\begin{array}{l}\text { DSM-5 için } \\
\text { önerilen } \\
\text { değişiklikler }\end{array}$ & $\begin{array}{l}\text { "Gerçek bir ölüm veya ölüm tehdidi, } \\
\text { ciddi yaralanma veya cinsel şiddete } \\
\text { maruziyet" }\end{array}$ & $\begin{array}{l}\text { - Travma uğrama yolları ayrı kriterlerle belirtilmiş } \\
\text { - } \\
\text { İlk defa tanımda cinsel şiddet verilmiş } \\
\text { - } \quad \text { Doğrudan deneyimleme vurgusu yapılarak } \\
\text { maruziyet şekli netleştirilmiş } \\
\text { - } \quad \text { Maruziyette tartışmalı dolaylı yollar } \\
\text { sınırlandırılmış-elektronik medya ile maruziyetin dışlanması } \\
\text { - } \quad \text { Mesleki maruziyetin ayrıca belirtilmesi } \\
\end{array}$ \\
\hline
\end{tabular}




\section{Kaynaklar}

American Psychiatric Association. (1952). Diagnostic and statistical manual of mental disorders, DSM-I. Washington, DC. (1. edition)

American Psychiatric Association. (1966) Diagnostic and statistical manual of mental disorders, DSM-II. Washington, DC.(2. edition)

American Psychiatric Association. (1980). Diagnostic and statistical manual of mental disorders, DSM-III. Washington, DC.(3.edition)

American Psychiatric Association. (1987). Diagnostic and statistical manual of mental disorders, DSM-III. Washington, DC.(3.edition revised)

American Psychiatric Association. (1994). Diagnostic and statistical manual of mental disorders, DSM-IV. Washington, DC(4. edition)

American Psychiatric Association. (2000). Diagnostic and statistical manual of mental disorders, DSM-IV. Washington, DC(4. edition revised)

American Psychiatric Association DSM-5 Task Force (2010) www.dsm5.org. Washington DC: American Psychiatric_Association.

Avina,C. \& O'Donohue,W. (2002) Sexual harassment and PTSD: is sexual harassment diagnosable trauma? Journal of Traumatic Stress, 15; 69-75.

Gerson B. (1992) Post-traumatic Stress Disorder: The History of a Recent Concept British Journal of Psychiatry 161;742-748

Jones, E \& Wessely, S (2005). Shell shock to PTSD, military psychiatry from 1900 to the Gulf war. Hove: Psychology Press.

Jones E,(2007) A Paradigm shift in the conceptualization of psychological trauma in the 20th century. Journal of Anxiety Disorders 21:164- 175

Kocatürk U,(2005) Açıklamalı Tıp Terimleri Sözlüğü, Nobel Tıp Kitapevi,9. Baskı, travma maddesi

Kardiner, A (1959) Traumatic neuroses of war. In: Arieti, S. (Ed.). American handbook of psychiatry. New York: Basic Books.Vol. 1:pp.245-257.
Maier T.(2006) Post-traumatic stress disorder revisited: Deconstructing the Acriterion, Thomas Medical Hypotheses 66;103106

Olff,M., Koeter,M.W. J.,Van Haaften, E.H., et al(2005) Impact of a foot and mouth disease crisis on post-traumatic stress symptoms in farmers. British Journal of Psychiatry, 186;165166.

Turnbull G.(1998) A review of post-traumatic stres disorder. Part 1: historical development and classification, Injury Vol. 29, No.2;87-91

Yehuda R, McFarlane AC. (1995) Conflict between current knowledge about posttraumatic stress disorder and its original conceptual basis, Am. J. Psychiatry, 152:1705-1713

Wilson J (1994) The Historical Evolution of PTSD Diagnostic Criteria: From Freud to DSM-IV, Journal of Traumatic Stress, Vol. 7, No. 4:681698

World Health Organisation(2010), International,Statistical Classification of Diseases and Related Health Problems 10thRevision(ICD 10), http://www.who.int/classifications/icd/ICD10Vol ume2_en_2010.pdf 
